\section{Criptococosis en el contexto del paciente inmunodeprimido}

Cryptococcosis in the context of the immunosuppressed patient

Angela Lastenia Figueroa Córdova

Master en seguridad y salud ocupacional Andec S.A,

https://orcid.org/0000-0002-6470-8281 drafigueroa@hotmail.es

Guayaquil - Ecuador

Edison Javier Siguencia Matute

Médico general

Hospital Clínica Kennedy,

https://orcid.org/0000-0002-8997-2361

javiersiguencia2017@gmail.com

Guayaquil - Ecuador

Mariana Isabel Batten Cuadrado

Médico general

Distrito 12D02 Pueblo Viejo-Urdaneta

https://orcid.org/0000-0002-8515-5049

marianitabatten.93@gmail.com

Guayaquil - Ecuador

Marcia Flor Lara Hernández

Especialista en Medicina Interna

Hospital de especialidades Teodoro

Maldonado Carbo,

https://orcid.org/0000-0002-0290-6194

dra.marcia_lara@hotmail.com

Guayaquil - Ecuador

Guayaquil - Ecuador

http://www.jah-journal.com/index.php/jah

Journal of American health

Julio - Diciembre vol. 3. Num. 2 - 2020

Esta obra está bajo una Licencia Creative

Commons

Atribución-NoComercial-CompartirIgual

4.0 Internacional.

RECIBIDO: 8 DE MARZO 2019

ACEPTADO: 18 DE NOVIEMBRE 2019 PUBLICADO: 4 DE JULIO 2020

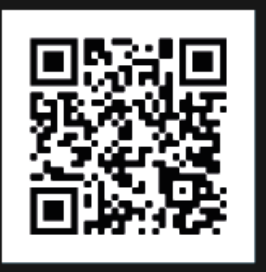

Scan this QR

code with your

smart phone or

mobile device to

read more papers

\section{RESUMEN}

La criptococosis es una enfermedad micótica invasiva, oportunista de distribución mundial, los excrementos de aves son el reservorio ambiental predominante, es causada por levaduras encapsuladas patógena en el género Cryptococcus, que ingresan al individuo generalmente por la vía respiratoria donde los pacientes inmunodeprimidos tales como pacientes $\mathrm{VIH} /$ sida, que realizan trasplante de órganos o quimioterapias, son los grupo más vulnerables, se sabe que es la tercera infección fúngica invasiva más común en receptores de trasplantes de órganos sólidos. Se pretende actualizar y describir la Criptococosis en el contexto del paciente inmunodeprimido con su nivel de evidencia mediante revisión documental; esta entidad continua siendo una enfermedad frecuente en inmunodeprimidos, la manifestación pulmonar es la presentación más usual así como las afecciones del sistema nervioso central, sin embargo destaca también otras formas cutáneas y óseas, regularmente sistémicas; la meningitis criptocócica representa más de 100,000 muertes especialmente en casos de paciente con inmunodeficiencia humana (VIH), se ha demostrado que el tratamiento con fluconazol y la anfotericina son terapias efectivas.

PALABRAS CLAVE: Criptococo spp, inmunodeprimido, micosis, diseminación

\section{ABSTRACT}

Cryptococcosis is an invasive fungal disease, worldwide opportunistic, bird droppings are the predominant environmental reservoir, it is caused by pathogenic encapsulated yeasts in the genus 
Cryptococcus, which enter the individual generally through the respiratory tract where immunosuppressed patients such as patients HIV / AIDS, which perform organ transplants or chemotherapies, are the most vulnerable group, it is the third most common invasive fungal infection in solid organ transplant recipients. The aim is to update and describe Cryptococcosis in the context of the immunosuppressed patient with his level of evidence through a documentary review; this entity continues to be a frequent disease in immunosuppressed patients, the pulmonary manifestation is the most usual presentation as well as the affections of the central nervous system, however it also highlights other cutaneous and bone forms, regularly systemic; cryptococcal meningitis represents more than 100,000 deaths especially in patients with human immunodeficiency (HIV), treatment with fluconazole and amphotericin has been shown to be effective therapies.

KEYWORDS: Cryptococcus spp, immunosuppressed, dissemination.

\section{INTRODUCCIÓN}

Es un patógeno capaz de brotes de enfermedades generalizadas en poblaciones vulnerables. (1), y se adquiere en la mayoría de las veces por vía respiratoria. (2). Existen dos variedades patógenas en el ser humano ambos dispuesto en zona tropicales y subtropicales el Cryptococcus neoformans var. neoformans, causante de la mayoría de las infecciones en pacientes inmunocomprometidos, y var. gattii, que afecta a individuos inmunocompetentes (3) (4).

En la mayoría de las infecciones criptocócicas se presentan en pacientes con VIH/SIDA con inmunosupresión avanzada. En otro tipo de pacientes inmunosuprimidos es menos conocida, pero ha ido aumentando en frecuencia y su mayor etiología es a causa de causa del Cryptococcus neoformans (5).

En América Latina, como ocurre en todo el mundo, C. neoformans causa más del $90 \%$ de los casos de criptococosis, que afecta predominantemente a pacientes con VIH (6). En muestras biológicas puede crecer fácilmente en medios de cultivo de hongos y bacterias de rutina. Además, la prueba de aglutinación de látex criptocócico se ha establecido como una herramienta de diagnóstico confiable con sensibilidades generales de 93-100\% (7).

Entre los tipos de criptococosis la pulmonar se presenta como una micosis invasiva oportunista importante en pacientes inmunocomprometidos, puede simular cáncer de pulmón, tuberculosis pulmonar, neumonía bacteriana y otras micosis pulmonares, tanto clínica como radiológicamente. Los nódulos pulmonares son la característica radiológica más común, pero no son específicos de la criptococosis pulmonar además de esta la afección del sistema nervioso central también es una forma usual en este grupo, aunque prácticamente cualquier órgano puede ser comprometido (8) (9).

En relación a Vertebral u ósea la forma de presentación más común es osteomielitis que ocurre en $5-10 \%$, la afectación de la columna es una de las más reportadas. (10) y la afección cutánea se clasifica como primaria o secundaria según la ruta de infección y forma de presentación en inmunodeprimidos es la cutánea diseminada. La criptococosis cutánea localizada se define 
como una afección en la que las lesiones están confinadas dentro de una parte limitada de la piel, no diseminadas sistémicamente al mismo tiempo y no se asocian con fungemía criptocócica ni antigenemía (11).

El Cryptococcus spp.transmite una alta carga de enfermedad entre los huéspedes inmunocomprometidos. Los médicos deben considerar numerosas variables y factores de manera dinámica para ofrecer el mejor tratamiento posible y controlar su respuesta al tratamiento (12).

Presentamos una actualización sobre los Criptococosis en el contexto del paciente inmunodeprimido con su nivel de evidencia mediante revisión documental.

\section{MATERIALES Y MÉTODOS}

Estudio descriptivo, documental cuyos datos fueron recolectados a través de fuentes secundarios en revistas indexadas, libros, sitios web publicados en los últimos cinco años 2015 al 2020 salvo los de relevancia científica de años previos, utilizando las palabras claves Criptococo spp, inmunodeprimido, micosis, diseminación, se escogió entre los idiomas el inglés y español se descartaron otros; seleccionado 26 artículos de los cuales 9 fueron imprescindibles y relevante para alcanzar el objetivo de esta investigación, los cuales se desglosan en serie de casos clínicos donde describe datos de filiación, sintomatología, y tratamiento efectuado a fin demostrar la presentación usual de la criptococosis en este grupo. Los criterios de inclusión fueron artículos de revisión narrativa cuyo tema central fue criptococosis en inmunodeprimidos.

\section{RESULTADOS}

Se detalla nueve estudios de casos relevantes relacionados a los factores de riesgos, síntomas y tratamiento más frecuentes descritos en la literatura en los últimos años.

Tabla \# 1: Casos sobre Criptococosis en Inmunodeprimidos

\begin{tabular}{|c|c|c|c|}
\hline Autor y tema & Descripción del Caso & $\begin{array}{l}\text { Condición } \\
\text { Factor } \\
\text { Riesgo }\end{array}$ & Tratamiento \\
\hline (13) & $\begin{array}{l}\text { Paciente de } 79 \text { años. Presentó } \\
\text { lesiones en dorso de la mano } \\
\text { derecha, con úlcera de } 2 \text { años } \\
\text { de evolución, que crecían } \\
\text { progresivamente y no } \\
\text { respondían al tratamiento } \\
\text { tópico con corticoides y } \\
\text { antibióticos. }\end{array}$ & $\begin{array}{l}\text { Cardiopatía } \\
\text { isquémica, } \\
\text { diabetes } \\
\text { mellitus tipo 2, } \\
\text { artropatía } \\
\text { periférica y } \\
\text { oligoartritis } \\
\text { seronegativa }\end{array}$ & $\begin{array}{l}\text { fluconazol } \\
400 \mathrm{mg} / \mathrm{dí} \\
\text { por vía oral, } \\
\text { presentando } \\
\text { muy buena } \\
\text { evolución, } \\
\text { tras } 6 \text { meses }\end{array}$ \\
\hline
\end{tabular}




\begin{tabular}{|c|c|c|c|}
\hline & & $\begin{array}{l}\text { Vivía en zona } \\
\text { rural, DMT2 }\end{array}$ & \\
\hline $\begin{array}{l}\text { (14) } \\
\text { (15) }\end{array}$ & $\begin{array}{l}\text { Paciente masculino, de } 47 \\
\text { años de edad, en su último } \\
\text { ingreso acude con fiebre de } \\
38,5 \text { OC, anuria de } 11 \text { horas, } \\
\text { disnea, gran toma del estado } \\
\text { general. El examen físico } \\
\text { mostró: ictericia, anasarca, } \\
\text { hepatoesplenomegalia, dolor } \\
\text { en ambos hipocondrios, } \\
\text { maniobra puño percusión y } \\
\text { puntos pielorenoureterales } \\
\text { bilaterales positivos y } \\
\text { lesiones cutáneas tipo } \\
\text { pápulas, eritematosas } \\
\text { ubicadas en manos, con dolor } \\
\text { a la palpación que } \\
\text { posteriormente se } \\
\text { diseminaron a cara, brazos, } \\
\text { piernas, tóraxy dorso }\end{array}$ & $\begin{array}{l}\text { Hipertensión } \\
\text { arterial, } \\
\text { hepatitis por } \\
\text { virus C e } \\
\text { insuficiencia } \\
\text { renal crónica } \\
\text { con trasplante } \\
\text { renal, con } \\
\text { rechazo agudo } \\
\text { al injerto- } \\
\text { Tratamiento } \\
\text { con } \\
\text { ciclosporina y } \\
\text { micofenolato } \\
\text { de mofetilo, } \\
\text { Vivía en medio } \\
\text { rural, Recibe } \\
\text { terapia } \\
\text { inmunosupreso } \\
\text { r. }\end{array}$ & $\begin{array}{l}\text { Paciente } \\
\text { fallece antes } \\
\text { de iniciar } \\
\text { tratamiento } \\
\text { específico } \\
\text { por choque } \\
\text { séptico } \\
\text { secundario a } \\
\text { repetidas } \\
\text { infecciones. }\end{array}$ \\
\hline (16) & $\begin{array}{l}\text { Paciente de } 55 \text { años se } \\
\text { presentó una historia de } \\
\text { paraparesia progresiva de } 4 \\
\text { meses. Además, múltiples } \\
\text { lesiones cutáneas en la cara y } \\
\text { el cuello, caracterizadas por } \\
\text { pápulas umbilicadas }\end{array}$ & $\begin{array}{l}\text { Las pruebas } \\
\text { serológicas } \\
\text { fueron positivas } \\
\text { para la } \\
\text { infección por } \\
\text { VIH }\end{array}$ & $\begin{array}{l}\text { El paciente } \\
\text { falleció a los } \\
2 \text { meses a } \\
\text { pesar del } \\
\text { tratamiento } \\
\text { con } \\
\text { anfotericina } \\
\text { B y } \\
\text { fluconazol. }\end{array}$ \\
\hline (17) & $\begin{array}{l}\text { Paciente masculino de } 45 \\
\text { años infectado por el VIH con } \\
\text { un recuento de linfocitos T } \\
\text { CD4 + de } 26 \text { células/ } \mu \text { L con } \\
\text { fiebre y pancitopenia. La } \\
\text { biopsia de médula ósea } \\
\text { reveló una hipocelularidad } \\
\text { por edad y ausencia de } \\
\text { fibrosis. }\end{array}$ & VIH-SIDA & $\begin{array}{l}\text { Inicialmente } \\
\text { fue tratado } \\
\text { con } \\
\text { anfotericina } \\
\text { B } \\
\text { desoxicolato } \\
\text { más } \\
\text { fluconazol }\end{array}$ \\
\hline
\end{tabular}




\begin{tabular}{|c|c|c|c|}
\hline (18) & $\begin{array}{l}\text { Mujer de } 63 \text { años de edad, } \\
\text { ama de casa, que consultó al } \\
\text { servicio de urgencias con } \\
\text { cuadro clínico de ocho días de } \\
\text { evolución consiste en } \\
\text { nauseas, vomito de contenido } \\
\text { alimenticio en repetidas } \\
\text { oportunidades, mareo, } \\
\text { vértigo y cefalea occipital } \\
\text { intensa, sin fiebre. }\end{array}$ & $\begin{array}{l}\text { Adulto mayor - } \\
\text { Manipulación } \\
\text { de excremento } \\
\text { de palomas }\end{array}$ & $\begin{array}{l}\text { La evolución } \\
\text { clínica de la } \\
\text { paciente fue } \\
\text { hacia el } \\
\text { deterioro } \\
\text { clínico con } \\
\text { estupor y } \\
\text { perdida de } \\
\text { reflejos } \\
\text { oculocefálic } \\
\text { os coma y } \\
\text { muerte }\end{array}$ \\
\hline (19) & $\begin{array}{l}\text { Paciente con trasplante } \\
\text { renal, de } 64 \text { años, con } \\
\text { meningoencefalitis a los } 6 \\
\text { meses } \\
\text { postratamiento. Presentó } \\
\text { Fiebre y pancitopenia. El } \\
\text { cultivo de aspirado de médula } \\
\text { ósea produjo levaduras } \\
\text { encapsuladas en gemación }\end{array}$ & $\begin{array}{l}\text { Transplante } \\
\text { renal, } \\
\text { Trabajador de } \\
\text { granja avícola- } \\
\text { Transplante } \\
\text { renal }\end{array}$ & $\begin{array}{l}\text { Anfotericina } \\
\text { B, con } \\
\text { posterior } \\
\text { cambio a } \\
\text { fluconazol } \\
\text { Pasados } 5 \\
\text { meses } \\
\text { presentó } \\
\text { recaída, y se } \\
\text { reinició el } \\
\text { tratamiento } \\
\text { con } \\
\text { evolución } \\
\text { favorable } \\
\text { hasta } 2 \text { años }\end{array}$ \\
\hline (20) & $\begin{array}{l}\text { Paciente femenina de } 75 \\
\text { años, de raza negra, presenta } \\
\text { pérdida hacía } 5 \text { semanas de la } \\
\text { sensibilidad y la motilidad } \\
\text { discreta en ambos miembros } \\
\text { inferiores, así como cefalea } \\
\text { occipital. En } 2 \text { consultas } \\
\text { previas se le diagnosticaron } \\
\text { cambios artrósicos en ambas } \\
\text { extremidades, perdida de la } \\
\text { sensibilidad y motilidad } \\
\text { discreta en ambos miembros } \\
\text { inferiores. }\end{array}$ & $\begin{array}{l}\text { Paludismo- } \\
\text { Adulto mayor, } \\
\text { VIH/sida } \\
\text { tratamientos } \\
\text { crónicos con } \\
\text { antiinflamatori } \\
\text { os no } \\
\text { esteroideos }\end{array}$ & $\begin{array}{l}\text { Se decidió } \\
\text { comenzar de } \\
\text { Anfotericina } \\
\mathrm{B} \text { a dosis de } \\
1 \quad \mathrm{mg} \\
/ \mathrm{kg} / \text { día, } \\
\text { asociado a fL } \\
\text { citosina } 100 \\
\mathrm{mg} / \mathrm{kg} / \text { día }\end{array}$ \\
\hline
\end{tabular}




\begin{tabular}{|c|c|c|c|}
\hline (21) & $\begin{array}{l}\text { Mujer de } 64 \text { años fue } \\
\text { derivada al Hospital debido al } \\
\text { empeoramiento del dolor } \\
\text { abdominal y la diarrea acuosa } \\
\text { durante } 2 \text { semanas. }\end{array}$ & $\begin{array}{l}\text { Enfermedad de } \\
\text { Crohn, } \\
\text { Inmunoterapia }\end{array}$ & $\begin{array}{l}\text { El paciente } \\
\text { Fue tratado } \\
\text { con éxito } \\
\text { con } \\
\text { anfotericina } \\
\text { B seguido de } \\
\text { fluconazol } \\
\text { con } \\
\text { resultado } \\
\text { satisfactorio. }\end{array}$ \\
\hline (22) & $\begin{array}{l}\text { Se trata de una mujer de } 49 \\
\text { años, Inició su padecimiento } \\
\text { dos meses previos a su } \\
\text { hospitalización con cefalea } \\
\text { universal intensa, } \\
\text { desorientación, alucinaciones } \\
\text { visuales, náuseas y vómito en } \\
\text { proyectil, cefalea } \\
\text { desorientación, alucinaciones } \\
\text { visuales y auditivas, náuseas y } \\
\text { vómitor }\end{array}$ & $\begin{array}{l}\text { Diabetes } \\
\text { mellitus tipo 2, } \\
\text { en tratamiento } \\
\text { con insulina } \\
\text { intermedia- } \\
\text { Cría aves de } \\
\text { corral, diabetes }\end{array}$ & $\begin{array}{l}\text { Se inició } \\
\text { manejo con } \\
\text { anfotericina } \\
\text { B con una } \\
\text { dosis inicial } \\
\text { de } 35 \text { mg por } \\
\text { día; } \\
\text { posteriorme } \\
\text { nte, } 50 \\
\text { mg/día y } \\
\text { fluconazol } \\
800 \text { mg por } \\
\text { día. }\end{array}$ \\
\hline
\end{tabular}

\section{DISCUSIÓN}

Molloy SF, en el 2018 (23) describe un total de 721 pacientes fueron aleatorizados donde detalla regímenes terapéuticos estándar de 2 semanas de anfotericina B más flucitosina y la monoterapia con fluconazol. La mortalidad en los grupos de régimen oral, anfotericina $B$ de 1 semana y anfotericina $B$ de 2 semanas fue del 18,2\%, respectivamente, a las 2 semanas y fue de $35.1 \%$, a las 10 semanas. Como fármaco asociado con anfotericina $B$, la flucitosina fue superior al fluconazol (71 muertes [31,1\%] frente a 101 muertes [45,0\%]; Una semana de anfotericina B más flucitosina se asoció con la mortalidad más baja a las 10 semanas. Los efectos secundarios, como la anemia severa, fueron más frecuentes con 2 semanas que con 1 semana de anfotericina B o con el régimen oral. Sin embargo, Hamil 2010 ya ha descrito la anfotericina $B$ liposómica proporciona una alternativa igualmente eficaz al desoxicolato de anfotericina $B$ convencional asimismo la anfotericina $B$ liposómica a una dosis de $3 \mathrm{mg} / \mathrm{kg} / \mathrm{día}$ se acompaña de significativamente menos efectos adversos, no obstante, son razones de cambio en esquema terapéuticos debido a la toxicidad sistémica (24) (25).

En relación a las manifestaciones clínicas está establecido que el órgano primario afectado son los pulmones, pero también se observa infección del sistema nervioso central y otros sistemas de órganos (26). Sin embargo la enfermedad pulmonar criptocócica es una infección importante y probablemente subregistrada, es imperioso generar nuevas investigaciones en 
los ámbitos epidemiológicos, métodos diagnósticos y el tratamiento para garantizar mejor evolución en los pacientes.

\section{CONCLUSIONES}

La criptococosis continúa siendo una infección importante en pacientes inmunodeprimidos y se asocia con una mortalidad general considerable y específica de la causa de la inmunodeficiencia como los pacientes VIH/SIDA, terapia con glucocorticoides, modificadores biológicos, uso de algunos inhibidores de la tirosina quinasa, trasplante de órganos sólidos, cáncer, afecciones como la sarcoidosis y la insuficiencia hepática.

La forma clínica más frecuente es la meningitis a pesar de que los pulmones son el portal de entrada para esta micosis, algunos pacientes tienen síntomas hasta varios meses antes del diagnóstico, mientras que otros presentan una enfermedad aguda de solo unos pocos días. La anfotericina B más flucitosina y 2 semanas de fluconazol más flucitosina han demostrado ser eficaces como terapia en entornos de recursos limitados.

\section{REFERENCIAS}

1. Eileen K Maziarz JRP. Triptococosis. Infect Dis Clin North Am. 2016 Marzo; 1(30): p. 179206.

2. Salazar Alvarado GM. Criptococosis del sistema nervioso central espectro fisiopatogénico. Int Nacional de Pediatría. 2015.

3. Tello M GEBVea. Criptococosis. Rev Med Risaralda. 2013; 19: p. 147-53.

4. García JL NA. Criptocococis.Una amenaza para pacientes inmunodeprimidos.. Gaceta Médica Espirituana. 2011; 3: p. s/d.

5. Magali Rodríguez Concepción NUFMEASJCMA. Infección por criptococos en el VIH-Sida. Revista de Ciencias Médicas de Pinar del Río. 2017 Marzo - Abril; 21(2).

6. Carolina Firacative JLMTIZECGdECL. El estado de la criptococosis en América Latina. Mem Inst Oswaldo Cruz. 2018; 7(113): p. e170554.

7. Qiaoling Ruan YZSCLZSZWZ. Criptococosis diseminada con abscesos múltiples recurrentes en un paciente inmunocompetente: informe de un caso y revisión de la literatura. BMC Infect Dis. 2017 Mayo 30; 1(17): p. 369.

8. Juan José Canciani. Agustín Dal Verme GPJLNANM. Osteomielitis vertebral asociada a nódulo pulmonar cavitado en paciente con trasplante renal: un desafío diagnóstico. Rev Argentina de Medicina. 2018; 6(1).

9. Findra Setianingrum RRRDWD. Criptococosis pulmonar: una revisión de la patobiología y los aspectos clínicos. Med Mycol. 2019 Febrero 1; 2(57): p. 133-150. 
10. Matías Pereira-Duarte GCMEGKCSMG. Criptococosis vertebral. Reporte de caso y revisión de literatura. Rev Chilena Infectol. 2019 Octubre; 5(36): p. 656-662.

11. Hiromitsu Noguchi TMUKMHMKHI. Criptococosis cutánea. Med Mycon J. ; 4(60): p. 101107.

12. Andrés F Henao-Martínez DBCCFP. Tratamiento de la criptococosis en pacientes inmunocomprometidos no VIH. Curr Opin Infect Dis. 2018 Agoosto; 4(31): p. 278-285.

13. Vázquez-Osorio IGRSRRM. Criptococosis cutánea primaria en paciente inmunocompetente. Dermatology Online Journal. 2016; 5(22).

14. Vázquez-Osorio IGRSRRM. Criptococosis cutánea primaria en paciente inmunocompetente. Dermatology Online Journal. 2016 Mayo; 5(22).

15. Yetter Cruz-León IATJDAEAH. Criptococosis cutánea primaria en un paciente con trasplante renal. Dermatol Perú. 2017; 2(27).

16. Igor Biscotto MMBRSREM. Criptococosis vertebral: una causa poco frecuente de una masa paravertebral. Rev. Soc. Bras. Medicina. Trop. 2020 Enero 24; 53.

17. Hareton Teixeira Vechi RCTALdORMOdSGRDdASMGFMBB. Infección micótica invasiva por Cryptococcus Neoformans Var. Grubii con médula ósea y afectación meníngea en un paciente infectado por el VIH: informe de un caso. BMC Infect Dis. 2019 Marzo 4; 1(19): p. 220.

18. Botero Juan Camilo RMJMMS. Criptococosis en una paciente inmunocompetente. Informe de un caso. Revista CES Meidina. 2003 Enero - Julio; 17(1): p. 52-53.

19. Lic. Ileana Paneque Rodríguez DJVTAAATICCDMMAyDEDA. Criptococosis en pacientes con trasplante renal. Presentación de un caso. Rev Cubana Med Trop. 2007 Mayo Agosto; 59(2): p. e1561-e3054.

20. Novoa LAM GCBFHBPC. Criptococosis meníngea en anciana con sida. Presentación de caso. Gaceta Médica Espirituana. 2012; 14(1).

21. Natthakit Chavapradit NA. Criptococosis diseminada en la enfermedad de Crohn: reporte de un caso. BMC Indect Dis. 2015 Diciembre 4; 1(18): p. 620.

22. Aguilar-García CR GAJOHGV. Criptococosis cerebral en una paciente inmunocompetente. Reporte de caso. Evid Med Invest Salud. 2015; 2(8): p. 84-88.

23. Molloy SF ea. Combinaciones antifúngicas para el tratamiento de la meningitis criptocócica en África. Engl J Med.. 2018; 378 (11): p. 1004. 
24. Hamill R. Comparación de 2 dosis de anfotericina B liposómica y desoxicolato de anfotericina $B$ convencional para el tratamiento de la meningitis criptocócica aguda asociada al SIDA: un ensayo clínico aleatorizado, doble ciego de eficacia y seguridad. Clinic infecct Dis. 2010; 51(2): p. 225.

25. Maria Tellez ea. La criptococosis cerebral y el síndrome inflamatorio de reconstitución inmune. Reporte de un caso]. Rev Med Chil. 2018; 146(12): p. 1481-1485.

26. Rahul Bollam MYTP. Criptococosis diseminada en un paciente inmunocompetente. Respir Med Case Rep. 2020 Marzo;: p. 101034. 